\title{
Discrepancies among student school lunch preferences, menu options, and consumption patterns in a low-income northern California high school
}

\author{
Kelly Fiori, Cindy Wolff, Keiko Goto, Martin Frigaard, Kenny Chan, Stephanie Bianco-Simeral \\ California State University, Chico
}

\begin{abstract}
USDA Nutrient Standard Menu Planning option, one of two National School Lunch Program options for school meal planning, has no requirements for fruit/vegetable servings and enables foodservice to serve nutrient-poor foods while remaining compliant with nutrition requirements. The objective of this research was to compare student reported preferences, meals offered, and meals selected over nine days. A preference survey was administered to 151 ninth grade students attending a low-income northern California high school. School lunch observations were conducted daily for an average of 418 to 584 students by trained researchers. Observation data demonstrated that $66 \%$ of students chose no servings of fruit or vegetables over the nine day period. In addition, $37 \%$ consistently selected the same one or two meals out of the 32 meals offered daily over a five day period. There was a discrepancy between reported meal preferences and observed meal selections. While 10\% selected pizza as their most preferred entrée, pizza comprised almost $30 \%$ of all daily entrée sales. This discrepancy is possibly due to the increased availability of pizza and/or limited availability of the more preferred entrees that either contain or are served with a fruit/vegetable. Findings indicate that a significant proportion of students may complete high school without ever selecting a serving of fruit or vegetables. A considerable gap between available food items and student preferences resulted in nutrient-poor food selection practices among 9th graders.
\end{abstract}

(c) 2011 Californian Journal of Health Promotion. All rights reserved.

Keywords: adolescents, food preference, school lunch, nutrition

\section{Introduction}

Adolescents have been reported to consume $47 \%$ of their total daily calories during the school day in the form of breakfast, lunch and snacks (Condon, 2009). Over 31 million children are provided with lunch each day by the National School Lunch Program (NSLP) that is federally funded by the United States Department of Agriculture (USDA) (USDA, 2009). USDA Nutrient Standard Menu Planning (NSMP), one of the National School Lunch Program options, has no requirements for fruit/vegetable servings and enables foodservice to serve nutrient-poor foods while remaining compliant with nutrition requirements. Few studies have examined how this particular lunch menu option may influence students' actual selection of foods from the school cafeteria including fruits and vegetables. This study examined the impact of the USDA Nutrient Standard Menu Planning on actual meals offered and meals selected among low-income high school students in northern California.

The National School Lunch Program (NSLP) was created to provide nutritionally balanced lunches at a reduced rate or for free to qualifying families. For a student to qualify for reduced price or free lunch in the NSLP, the student's family income must be at or below $185 \%$ of the poverty level. Participating schools must provide lunches that meet the 1995 Dietary Guidelines for Americans. These guidelines recommend that no more than $30 \%$ of calories come from fat and less than $10 \%$ from saturated fat. The meals must also provide at least one-third of the 1989 Recommended Dietary Allowances for calories, protein, vitamin $\mathrm{A}$, vitamin $\mathrm{C}$, iron and calcium (USDA, 2009). As long as these guidelines are 
met, the school districts are allowed to choose from several menu planning options (Gordon et al., 2009).

All menu planning options fall under either a food based or nutrient standard category. The Food Based Menu Planning (FBMP) category requires that each meal consist of five food items (meat/meat alternate, grains/breads, two different fruits/vegetables, and fluid milk) with specific serving sizes for each item to help ensure that nutritional guidelines are met. Schools choosing to use the FBMP are not required to provide nutritional analyses for their menus (CDOE, 2009).

In contrast, the NSMP allows foodservice staff to create menus without adherence to specific guidelines related to type of food or serving size. This nutrient based planning approach requires that nutrient analyses are conducted in order to ensure that nutrient standards are met (CDOE, 2009). The meal must consist of an entrée, milk, and one or more side dishes. Foods considered as side dishes are fruit, vegetables, dessert, or a bread/grain item (Gordon et al., 2009). All menu items, condiments/garnishes, and foods of minimal nutritional value must be included in the nutrient analysis (CDOE, 2009).The nutrient analysis is based on a five day average and must meet the guidelines previously mentioned for fat, saturated fat, calories, protein, vitamin A, vitamin $\mathrm{C}$, iron and calcium. The nutrient based planning approach does not require a serving of fruit or vegetable since it is assumed that these foods will be provided in order to meet the vitamin $\mathrm{A}$ and $\mathrm{C}$ nutrient requirements.

While the food based approach requires that schools offer five food items and students must take full servings of at least three different food items, the nutrient standard approach requires that schools offer a minimum of three menu items (two of the three items must be an entrée and milk) and students must select at least two menu items. The NSMP approach has no requirement for fruit/vegetable servings because it is assumed that fruits/vegetables will be offered and selected in order to meet vitamin A and $\mathrm{C}$ requirements. Potential shortcomings with use of the NSMP option include that 1) it enables foodservice to serve nutrient-poor foods while remaining compliant with nutrition requirements, and 2) it is assumed that students will select a variety of foods to meet requirements even though students have the option to select the same meal every day.

Results from the School Nutrition Dietary Assessment (SNDA) III indicate that $55 \%$ of high school NSLP students self-reported consumption of fruit, juice, and/or vegetables (excluding French fries) during the prior school day (Condon, 2009). Results from this same survey indicate that NSLP participating students had an increased likelihood of meeting vitamin and mineral recommendations compared with non-participating students (Clark, 2009). The SNDA III also surveys school district food service managers and asks their provision of school menu information. Results from this menu survey component of the SNDA III indicate that $95 \%$ of high school menus offer students at least one serving of fruit or fruit juice and $91 \%$ offer at least one serving of vegetables (excluding French fries) with each entrée option. Previous research indicates that even though school menus list a fruit or vegetable with every entrée, this may not be reflective of actual practice (Condon, 2009). The discrepancy between 55\% of SNDA III students reporting consumption of fruit and vegetables and the $90 \%$ or more of SNDA III high school menus reported by district food service staff as providing fruit and vegetables suggest the possibility that school menus may not accurately reflect what is actually offered to students. This possibility is of additional concern because schools following the NSMP category are not required to serve a fruit or vegetable within the entrée or as a side.

Research has shown a strong association between adolescent consumption patterns and food availability (Story et al., 2002; NeumarkSztainer et al., 2005). Research has also demonstrated a positive relationship between preferences and consumption (Baxter and Thompson, 2002; Rasmussen et al., 2006). Baxter and Thompson (2002) found a significant association between preferences and consumption among their study participants. A 
review article examining determinants of fruit and vegetable consumption among children and adolescents identified preferences and home availability/accessibility as significant factors associated with fruit and vegetable consumption (Rasmussen et al., 2006).

Nutrition professionals have an opportunity to influence student consumption patterns by providing healthy school meals in combination with various school-based nutrition education strategies. However, if healthier entrées are not provided or are provided in limited quantities, students may not receive adequate exposure to an opportunity to change their consumption patterns or even continue established patterns of selecting meals that consistently include a fruit or vegetable.

To date, little is known about actual cafeteria food selection patterns among high school students, as well as factors associated with those patterns such as food preferences and food availability. Student food choices are influenced by school menu options such as the USDA NSMP option. The objective of this research was to compare high school reported lunch preferences, actual meals offered, and actual meals selected among high school students participating in the USDA NSMP option.

\section{Methods}

\section{Subjects}

A convenience sample of 151 low-income, ethnically diverse 9th grade students attending health and geography classes was selected to complete a school lunch food preference survey. In addition, observation data of school lunch selections were collected for an average of 418 to 584 students daily at the high school cafeteria over a nine day period. Via student identification numbers, we were able to track all cafeteria selections for those 9th grade students completing the preference survey. This study was approved by the Institutional Review Board at California State University, Chico.

\section{Instruments and Procedures}

A four-page school lunch preference survey entitled, "You Tell Us," was administered to 9th grade students in health and geography classes to assess their school lunch preferences. The survey questions consisted of school entrée preferences, their reasons for food selection, and demographic information. The survey was approved by the Network for a Healthy California, CA Dept. of Public Health.

Each participating teacher received a packet containing parent consent forms, a teacher instruction sheet, and the student surveys. The parent consent forms were distributed before the survey was administered. On the day of the survey, the teacher read aloud the instructions provided and distributed the surveys. To ensure confidentiality, the students placed their completed surveys in a manila envelope with the last student sealing it and the teacher signing across the seal.

Observation tracking forms were used to record cafeteria foods selected by all students purchasing meals. Trained university student researchers were positioned at each of nine cafeteria windows during the lunch period for nine days in February and March 2009. Observation tracking forms were used to record foods selected by all high school students purchasing meals during the nine lunch periods. With this method we were able to determine whether fruits, vegetables, or juice were included in the lunch items selected by each individual student.

The California Department of Education's Nutrition Services Division requires that school districts participating in the NSLP provide production records for every school day. The production records, which represent food sales from the entire student population, must include type and quantity of food used, total number of persons served, number of portions served, and portion sizes for all foods. Foodservice staff provided production records for February and March 2009. These production records enabled us to compare food preferences indentified on the surveys with actual foods selected by students and with our observation data for student selections. 


\section{Data Analysis}

Data were analyzed using SPSS (version 16.0, 2008, SPSS Inc, Chicago, IL.) Food production records were analyzed for totals and types of meals and fruit and vegetable servings provided. Descriptive statistics were computed for all variables, including means and standard deviations for continuous variables and frequencies for categorical variables. We also examined the relationship between preference and actual selection of certain foods based on observation data among the 151 students who participated in the survey. Via student identification numbers, we were able to track all cafeteria selections for those 9th grade students completing our preference survey. McNemar tests were used to examine the association between the preference and selection of pizza, as well as the association between the preference and selection of entrée containing fruits or vegetables. Statistical significance was established at $\mathrm{p}<.05$.

\section{Results}

\section{Characteristics of 9th grade students}

Table 1 describes the demographic characteristics of the 151 ninth grade students who completed the You Tell Us food preference survey.
The table shows that $41 \%$ of the students were non-Hispanic White, $21 \%$ are Asian (primarily Hmong), $12 \%$ are Latino, $9 \%$ are Native American, 3\% are Black, and 14\% other.

\section{Table 1}

Demographic characteristics of $9^{\text {th }}$ grade students who participated in the entrée preference survey

\begin{tabular}{lcc}
\hline Characteristics & $\mathbf{n}^{*}$ & Percent \\
\hline Gender & 76 & 51 \\
$\quad$ Male & 72 & 49 \\
Female & & \\
Age & & \\
13 & 3 & 2 \\
14 & 90 & 60 \\
15 & 56 & 37 \\
16 & 2 & 1 \\
& & \\
Race & & \\
White & 60 & 41 \\
Asian & 31 & 21 \\
Native American & 13 & 9 \\
Black & 4 & 3 \\
Latino & 18 & 12 \\
Other & 21 & 14 \\
\hline
\end{tabular}

* $\mathrm{n}$ ranges from $115-151$ by variable

\section{Figure 1}

Description of fruit and vegetable $(f / v)$ content of high school meals $(n=11,007-10,124)$ including and excluding fruit juice and French fries

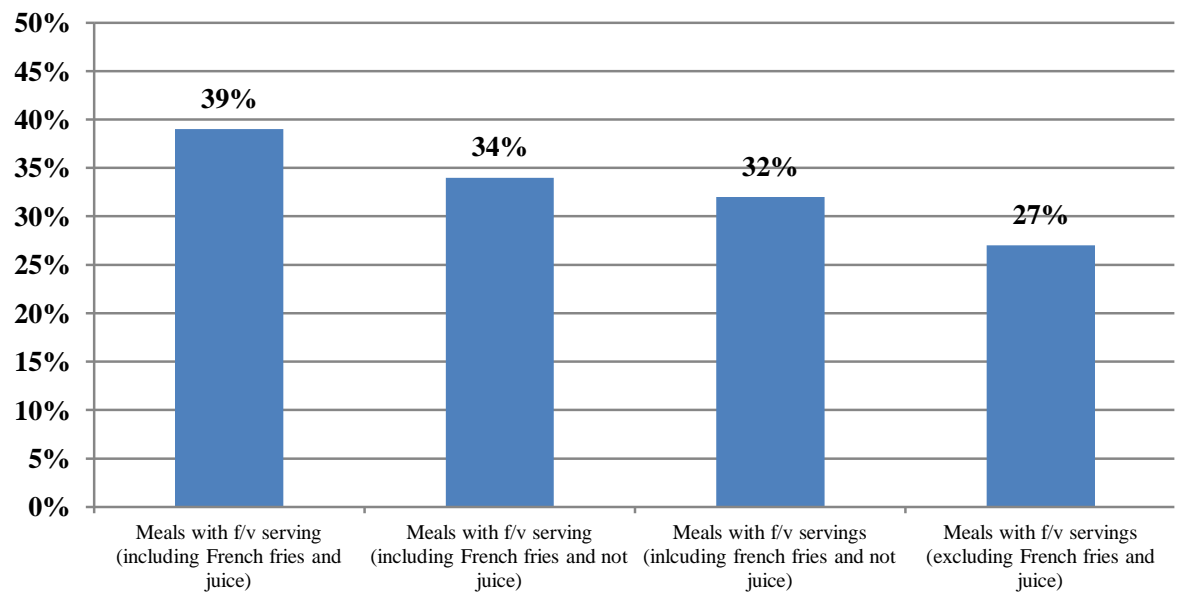


Summary of meals with and without at least one serving of fruit or vegetable based on visual observations of meals and production records

Figure 1 displays actual selection rates for all meals served over a nine day period based on visual observations. Only $34 \%$ of all observed meals contained a serving of a fruit, vegetable, or juice, or stated conversely, $66 \%$ of observed meals contained no servings of fruit or vegetables either within the entrée or as a side option. This $66 \%$ figure includes juice as a fruit serving, but excludes French fries as a vegetable serving. Juice was the only fruit/vegetable serving for $7 \%$ of the students while $5 \%$ of the students were provided French fries as their only fruit/vegetable serving.

As previously mentioned, the school food service production records represent sales from the entire student population purchasing lunch. The findings from the observation data (Figure 1) that $66 \%$ of all lunches contained no servings of fruit or vegetables either as part of the entrée or as a side option, is fairly consistent with findings from the production records data. According to the production records, 53\% of total lunches served in February and March did not provide at least one serving of fruit or vegetable. It is noteworthy that the production records data represent the highest possible rate of lunches containing at least one fruit and vegetable serving because this method assumes that no student selected two servings from the choices of a piece of fruit, a vegetable salad, or juice. With regard to the analysis of the production data, we assumed that no student selected more than a single serving of these three fruit and vegetable options even though our visual observations confirmed that some students did, in fact, select a serving of fruit or salad plus a serving of juice or two pieces of fruit.

\section{Number of different entrée selections among 9th grade students observed over five days}

We also assessed to what degree students varied their selection of lunch entrées. We assumed that
Table 2

Frequency of different entrée selections among 9th grade students observed over five days $(n=85)$

\begin{tabular}{ccc}
\hline $\begin{array}{c}\text { Number of } \\
\text { different entrées } \\
\text { selected }\end{array}$ & $\begin{array}{c}\text { n }(\% \text { of } \\
\text { students } \\
\text { observed })\end{array}$ & $\begin{array}{c}\text { Cumulative } \\
\%\end{array}$ \\
\hline 1 & $8(10)$ & 10 \\
2 & $22(27)$ & 37 \\
3 & $41(49)$ & 85 \\
4 & $13(13)$ & 99 \\
5 & $1(1)$ & 100 \\
Total & 85 & \\
\hline
\end{tabular}

a high level of variance in entrée selection would help protect students from the consistent selection of entrées that did not provide at least one serving of fruit or vegetable as part of the meal. Table 2 shows the results of the level of variance in entrée selections by the students who completed preference surveys. Of these 151 ninth graders, $55 \% \quad(n=85)$ obtained school lunches on at least five days during our nine day observation period. Thirty-seven percent of these students selected only one or two different entrées over a five day period while $85 \%$ of them selected three or fewer entrées. Hence, there is a fairly low degree of variance for entrée selections among this group of ninth graders.

\section{Comparison between survey preference data and actual entrée selections among ninth grade students}

We also compared preference data with actual entrée selections for the 151 ninth grade students completing the preference survey. Figure 2 demonstrates the relationship between student preference of pizza for their entrée and their actual selection rates for this entrée. The McNemar test revealed that the pizza preference was significantly different from actual pizza selection $(p<0.001)$ and that the availability of this and other food items in the cafeteria appeared to be a factor associated with the actual selection of food items. As shown in Figure 2, 
Figure 2

\section{A significant percent of students select pizza at least once during the five observed days despite a reported lack of preference for pizza (McNemar test, $p<0.001)$}

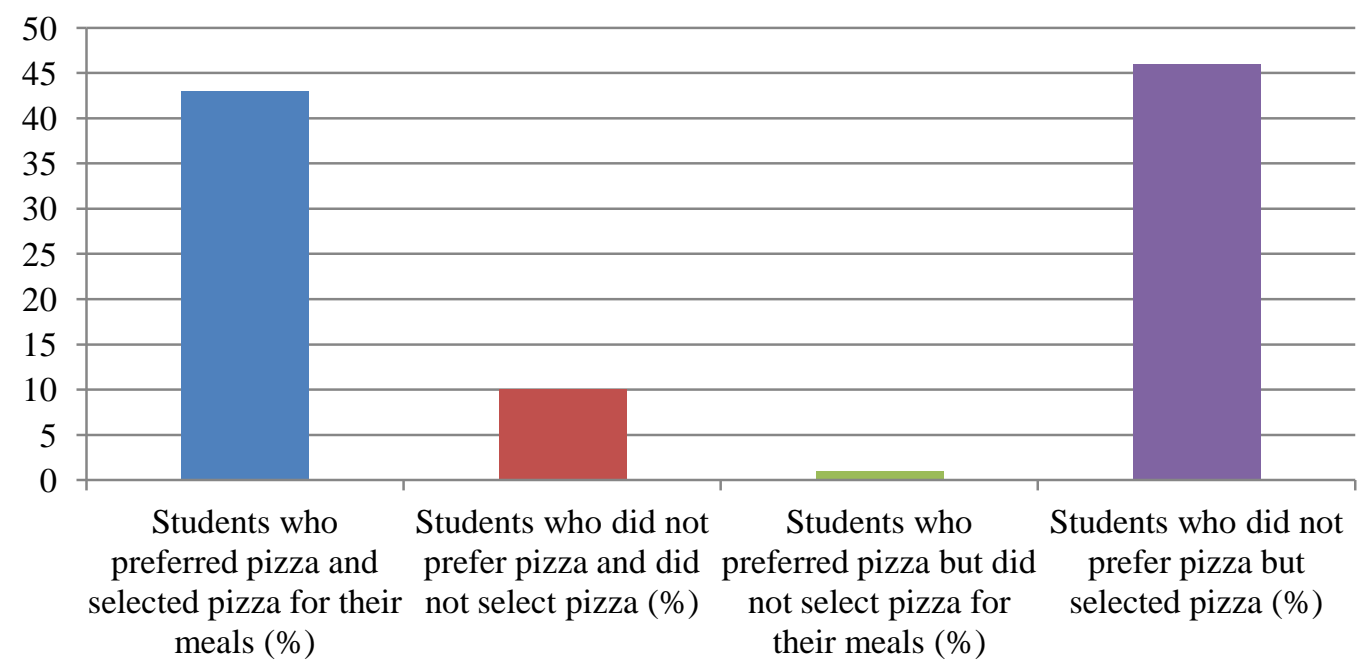

$46 \%$ of the students ended up selecting pizza at least once during the five observed days even though pizza was not a most preferred entrée for them. On the other hand, only $1 \%$ of the students did not select pizza despite their reported preference for pizza. Furthermore, $17 \%$ of students did not prefer pizza but selected pizza for $\geq 50 \%$ of their meals (data not shown). Likewise, $22 \%$ of the students reported preferences for entrées with fruits or vegetables, such as yogurt parfait, but ended up selecting those entrées for less than $50 \%$ of their meals.

These discrepancies were further examined by analyzing the relationship between the results of the preference survey and production records (Table 3). There were three entrées (pizza, chicken strips, and yogurt parfait) for which there was a considerable difference between the ninth grade students' preference rates and the actual selection rate obtained from production records. Of these three entrées, the preference rates for chicken strips and yogurt parfait greatly outweighed the actual selection of these foods. Conversely, the actual selection rate for pizza was more than double the preference rate. While $10 \%$ of 9 th grade students selected pizza as a first choice preference, an average of $30 \%$ ended up purchasing pizza. Furthermore, both visual observation data and food production data indicate that there was ample pizza available at the point of selection compared to limited availability for the chicken strips and yogurt parfait, both highly preferred selections.

\section{Discussion}

The objective of this research was to examine student reported preferences, actual meals offered, and meals selected over five days among ninth grade students. To our knowledge, this is the first study that systematically examined discrepancies between students' stated food preferences and their actual food selections in a school setting.

Observation data demonstrated that only $34 \%$ of all observed meals provided a serving of a fruit, vegetable, or juice. As discussed previously, the foodservice production record numbers were 
Table 3

Ninth grade entrée preference survey rates compared to actual entree selections by $9^{\text {th }}-12^{\text {th }}$ grade students based on school food service production records

\begin{tabular}{|c|c|c|c|c|}
\hline \multirow[t]{2}{*}{ Entrees* } & \multicolumn{2}{|c|}{$\begin{array}{l}\text { Most preferred entrees } \\
\qquad(n=151)\end{array}$} & \multicolumn{2}{|c|}{$\begin{array}{l}\text { Entrees selected at } \text { POS }^{* *} \\
\qquad(\mathrm{n}=473)\end{array}$} \\
\hline & $\mathbf{n}$ & $\%$ & $\mathbf{n}$ & $\%$ \\
\hline Pizza - pepperoni or cheese & 15 & 10 & 139 & 30 \\
\hline $\begin{array}{l}\text { Spicy Chicken Sandwich } \\
\text { (spicy or chipotle) }\end{array}$ & 18 & 12 & 40 & 9 \\
\hline $\begin{array}{l}\text { Chicken Wrap } \\
\text { (Caesar, spicy, or chipotle ) }\end{array}$ & 13 & 9 & 32 & 7 \\
\hline Turkey Bacon Ciabatta or Wrap & 3 & 2 & 28 & 6 \\
\hline $\begin{array}{l}\text { Bean Burrito (fiesta bean, big and } \\
\text { spicy, or chicken rice) }\end{array}$ & 2 & 1 & 25 & 5 \\
\hline Chimichanga & 7 & 5 & 24 & 5 \\
\hline Chicken Strips & 17 & 11 & 24 & 5 \\
\hline Asian: Minh Egg Roll & 3 & 2 & 23 & 5 \\
\hline Asian: Chicken Noodle & 1 & 1 & $\mathrm{~N} / \mathrm{A} * * *$ & $\mathrm{~N} / \mathrm{A} * * *$ \\
\hline Asian: Teriyaki Rice & 1 & 1 & 20 & 4 \\
\hline Ham/Turkey Sub Sandwich & 6 & 4 & 21 & 4 \\
\hline Cheeseburger & 7 & 5 & 15 & 3 \\
\hline Veggie Burger & 1 & 1 & $\mathrm{~N} / \mathrm{A} * * *$ & $\mathrm{~N} / \mathrm{A} * * *$ \\
\hline Tornado Steak/Cheese & $\mathrm{N} / \mathrm{A} * * *$ & 0 & 16 & 3 \\
\hline Yogurt Parfait & 10 & 7 & 13 & 3 \\
\hline Chicken Salad (Caesar or spicy) & 2 & 1 & 10 & 2 \\
\hline Peanut Butter and Jelly Sandwich & 2 & 1 & 10 & 2 \\
\hline Chili Bowl & 1 & 1 & 4 & 1 \\
\hline Chili Dog & 2 & 1 & 3 & 1 \\
\hline Nachos Supreme & 7 & 5 & 6 & 1 \\
\hline Calzone & 1 & 1 & 4 & 1 \\
\hline Chef Salad & $\mathrm{N} / \mathrm{A} * * *$ & 0 & 4 & 1 \\
\hline Tuna Ciabatta & $\mathrm{N} / \mathrm{A}^{* * *}$ & 0 & 4 & 1 \\
\hline Taco and Chips & 2 & 1 & 6 & 1 \\
\hline Vegetarian Salad & 1 & 1 & 2 & 0 \\
\hline *BBQ Rib Sandwich & 12 & 8 & $\mathrm{~N} / \mathrm{A} * * *$ & $\mathrm{~N} / \mathrm{A} * * *$ \\
\hline *Famous Chicken Bowl & 6 & 4 & $\mathrm{~N} / \mathrm{A} * * *$ & $\mathrm{~N} / \mathrm{A} * * *$ \\
\hline$*$ Crispito and Oven Fries & 1 & 1 & $\mathrm{~N} / \mathrm{A} * * *$ & $\mathrm{~N} / \mathrm{A} * * *$ \\
\hline *Spaghetti and Garlic Bread & 5 & 3 & $\mathrm{~N} / \mathrm{A} * * *$ & $\mathrm{~N} / \mathrm{A} * * *$ \\
\hline *Other & 5 & 3 & $\mathrm{~N} / \mathrm{A} * * *$ & $\mathrm{~N} / \mathrm{A} * * *$ \\
\hline Total & 151 & 102 & 473 & 100 \\
\hline
\end{tabular}

* Daily specials are excluded because these five entrees are not offered every day.

** $\quad \mathrm{POS}=$ point of selection; foods are ranked according to POS selection percent.

*** N/A = not applicable. There was no preference or production data for these entrees. They were not listed on the school menu or production records. 
interpreted to provide best case scenarios for the percent of students being provided with at least one fruit or vegetable serving. Production record data do not capture whether a fruit or vegetable serving was purchased (or displayed) by a staff member rather than provided to a student. Nor do the production data specify whether the same student selected two servings from the choices of a piece of fruit, a vegetable salad, or juice. Observation data reported in Table 2, however, capture actual fruit and vegetable selections by each student. Hence, we are confident that the observation data reported in Table 2 are more accurately representative of actual fruit and vegetable selections by these high school students.

Production records show that only $52 \%$ of the entrees served contained a fruit, vegetable or juice serving in contrast to the $91 \%$ and $95 \%$ of the high school district menus offering a vegetable (excluding French fries) or fruit serving, respectively, according to the SNDAIII. More than half of all schools participating in the SNDA-III used the FBMP option, while only $30 \%$ used the NSMP (Condon, 2009). Many California school districts utilize the USDA NSMP option, in which there are no requirements for fruit/vegetable servings. The rationale for this option is that the fruits and vegetables included in the school menu ensure that the vitamin and mineral requirements are met. It is assumed that students will select a variety of foods to meet requirements even though students have the option to select the same meal every day. However, students' actual meal selection patterns and verification that nutrient requirements are met are rarely examined.

The current study demonstrates that more than one-third of these high school students consistently selected the same one or two meals over a five day period. This finding coupled with the high rate of students selecting no fruit or vegetable suggests that a significant proportion of students may complete their entire high school education without ever being provided a fruit or vegetable as part of their school lunch. Thus, the assumption that the NSMP option meets USDA nutrient standards is not validated for this particular district, and most likely for other districts that utilize this same menu planning option.

In this study, 9th grade students' entrée preference data were compared with actual entrée selections using both observational data and foodservice production records. While prior research has shown that high school student food sales results are consistent with self-reported lunch preferences (Ware-Kauzer et al., 2008), this current study indicates that there is a considerable gap between what is available and what students prefer. Specifically, for the three most preferred entrees (pizza, chicken strips, and yogurt parfait) there can be considerable difference between ninth grade student preference rates and actual selection rates obtained from foodservice production records. According to the production records, while 10\% of 9th grade students identified pizza as a first choice preference, an average of $30 \%$ ended up purchasing pizza. The comparison between preference data from the survey and observation data further revealed that $46 \%$ of the students ended up selecting pizza for their meal even though pizza was not a most preferred entrée for them.

Environmental influences on food selections, such as food availability, have been well documented (Popkin et al., 2005). In this study, availability appears to be a key variable affecting students' cafeteria selections. Both visual observation data and food production data document that there was ample pizza available at the point of selection compared to limited availability for the chicken strips and yogurt parfait, both highly preferred selections. Production records provide no way of identifying if a student wanted to select a food item, but that particular item was unavailable at the time the student had to make his/her food selections. For example, production records show that on average only 15 yogurt parfait entrées were prepared out of a total of 550 total entrées were prepared. If students arrived at the cafeteria after the 15 parfaits were sold, they may not know that parfaits were even offered. Nor will they have the opportunity to try the parfait and accurately rate their preference for 
this entrée. If given an opportunity to try the parfait, students may prefer the parfait over other entrée options. Hence, in agreement with previous research (Neumark-Sztainer et al., 2005), study results indicate that availability greatly influences students' cafeteria selections and may not reflect their stated preferences. It is likely that students simply choose what is available to them.

Production record data documented that several items listed on the school menu were either not offered or were not easily available to all students. These items included whole fruit, side salads, yogurt parfaits, salad entrées, juice, and sandwich entrées. Less expensive, convenience items such as pizza and Chimichangas appeared to have been more plentiful, whereas more labor-intensive items (e.g. yogurt parfaits, salads, and sandwiches) were prepared in smaller quantities that were quickly sold out. Hence, students arriving later to the cafeteria may find a different array of foods available for selection compared to students arriving earlier. Furthermore, no fruit or vegetable serving was provided with the pizza entrée at the time of this study.

\section{Limitations}

This study has several limitations. Food production records showed that a total of 5,052 lunches were served over our nine day observation period. Our total of 4,481 observed lunches indicates that there was a difference of 571 lunches between observations and production records over these nine days. This may be due to staff/teachers taking/purchasing meals or misreporting of data on production records. Second, because meal selections were observed in the winter, fresh fruit and vegetable selection may have been affected. Third a convenience sample was used for this study. Finally, this sample of northern California high school students might not be representative of the general populations of low-income high school students in the United States.

\section{Conclusion}

While behavior changes through nutrition education continue to be emphasized for obesity prevention among adolescents, the inequity in environmental conditions for healthy eating, including school food policies and practices, may contribute substantially to the health disparities among adolescents in the US population. This study demonstrates that a considerable gap exists between students' stated school lunch preferences, food service production data, and actual food selections. It is apparent that the NSMP option does not appear to safeguard nutrient health for these high school students since more than $60 \%$ (best case scenario) left the cafeteria with no fruit or vegetables as part of their school lunch. Many schools rely on the convenience and lower cost of pre-prepared processed items such as pizza. It appears that school foodservice personnel would need guidance on appropriate nutrientbased specifications (Gordon et al, 2009). Additional empirical studies using observations rather than self-reported questionnaires are needed to evaluate the impact of the school food environment and school meal policies on actual food selections and their impact on the nutritional health of high school students.

\section{Acknowledgements}

This study was supported by in part, by the Network for a Healthy California and by California State University, Chico. The authors wish to thank the faculty and students at California State University, Chico and the Network for a Healthy California school partners, staff and study participants for their support.

\section{References:}

Baxter, S.D., \& Thompson, W.O. (2002). Fourth-grade children's consumption of fruit and vegetable items available as part of school lunches is closely related to preferences. Journal of Nutrition and Education Behavior, 34(3), 166-171.

California Department of Education (CDOE). School Menu Planning Options, 2009. Available at: http://www.cde.ca.gov/ls/nu/he/smi.asp. Accessed July 11,2010. 
Fiori K., Wolff, C., Goto, K., Frigaard, M., Chan, K., \& Bianco-Simeral, S. / Californian Journal of Health Promotion 2011, Volume

California Department of Public Health (CDPH). California Teen Eating, Exercise and Nutrition Survey (CAL-TEENS), 2007. Available at: http://www.cdph.ca.gov/programs/cpns/Documents/NetworkREU-CalTEENS-SurveyInstrument-2002.pdf. Accessed July 20, 2010.

California Department of Public Health (CDPH). Network for Healthy California Nutrition Education Survey (NES), 2007-08. Available at: http://www.cdph.ca.gov/programs/cpns/Documents/Network-REU-BackgroundforNES-20072008.pdf. Accessed July 20, 2010.

Clark, M.A. (2009). Nutritional quality of the diets of US public school children and the role of the school meal programs. Journal of the American Dietetic Association, 109(2), S44-S56.

Condon, E.M. (2009). School meals: types of foods offered to and consumed by children at lunch and breakfast. Journal of the American Dietetic Association, 109(2), S67-S78.

Gordon, A.R., Crepinsek, M.K., Briefel, R.R., Clark, M.A., \& Fox, M.K. (2009). The third School Nutrition Dietary Assessment Study: Summary and Implications. Journal of the American Dietetic Association, 109 (1), S129-S35.

Neumark-Sztainer, D., French, S.A., Hannan, P.J., Story, M., \& Fulkerson, J.A. (2005). School lunch and snacking patterns among high school students: Associations with school food environment and policies. International Journal of Behavioral Nutrition and Physical Activity, 2(14).

Popkin, B.M., Duffey, K., \& Gordon-Larsen, P. (2005). Environmental influences on food choice, physical activity and energy balance. Purdue University Ingestive Behavior Research Center Symposium Dietary Influences on Obesity: Environment, Behavior and Biology, 86(5), 603-13.

Rasmussen, M., Krølner, R., Klepp, K.I., Lytle, L., Brug, J., Bere, E., \& Due, P. (2006). Determinants of fruit and vegetable consumption among children and adolescents: a review of the literature. Part I: quantitative studies. International Journal of Behavioral Nutrition and Physical Activity, 3(22) Available at: http://www.ncbi.nlm.nih.gov/pmc/articles/PMC1564033/pdf/1479-5868-3-22.pdf. Accessed July 20, 2010.

Story, M., Neumark-Sztainer, D., \& French, S. (2002). Individual and environmental influences on adolescent eating behaviors. Journal of the Americian Dietetic Association. 102 (3), S40-S51.

United States Department of Agriculture (USDA). National School Lunch Program, (2009). Available at: http://www.fns.usda.gov/cnd/Lunch/AboutLunch/NSLPFactSheet.pdf. Accessed July 20, 2010.

Ware-Kauzer, K., Wolff, C., Bianco-Simeral, S., \& Levi, A. (2008). Assessing Incongruity among School Food and Beverage Marketing, High School Student Weight Management Beliefs and Practices, Food Preferences, and School Food Purchasing. Poster presented at the California Dietetic Association conference. March 2008. Los Angeles..

$\underline{\text { Author Information }}$

Kelly Fiori, MS

California State University, Chico

Cindy Wolff, PhD, MPA, RD

Professor

Director, Center for Nutrition and Activity Promotion California

State University, Chico

Department of Nutrition and Food Sciences

Keiko Goto, $\mathrm{PhD}^{*}$

Associate Professor

California State University, Chico

Department of Nutrition and Food Sciences

CSU, Chico 0002

Chico, CA 95929-0002 
Fiori K., Wolff, C., Goto, K., Frigaard, M., Chan,K., \& Bianco-Simeral, S. / Californian Journal of Health Promotion 2011, Volume 9, Issue 2, 29-39

Telephone Number: (530) 898-6767

Fax: (530) 898-5586

E-mail: kgoto@csuchico.edu

Martin Frigaard, BS

California State University, Chico

Kenny Chan, $\mathrm{PhD}$

Professor

California State University, Chico

Department of Finance and Marketing

Stephanie Bianco-Simeral, MS, RD

Assistant Professor

California State University, Chico

Department of Nutrition and Food Sciences

* corresponding author 